\title{
Orbital apex syndrome associated with diffuse hypertrophic pachymeningitis in isolated neurosarcoidosis
}

Síndrome da fissura orbitária superior associada a paquimeningite hipertrófica difusa na neurosarcoidose isolada

Nara Texeira BARBOSAㄱ, Bárbara Camille Rocha GOMES ${ }^{1}$, Marcelo CAGY', Mariana SPITZ1,2, Ana Carolina Andorinho de Freitas FERREIRA

A 43-year-old woman reported acute onset of right retroorbital headache followed by ptosis, paralysis of extraocular muscles, and subsequently amaurosis, characterizing an orbital apex syndrome ${ }^{1}$. Brain MRI showed diffuse pachymeningitis with leptomeningeal and parenchymatous involvement (Figure 1). CSF analysis was unremarkable. ACE and

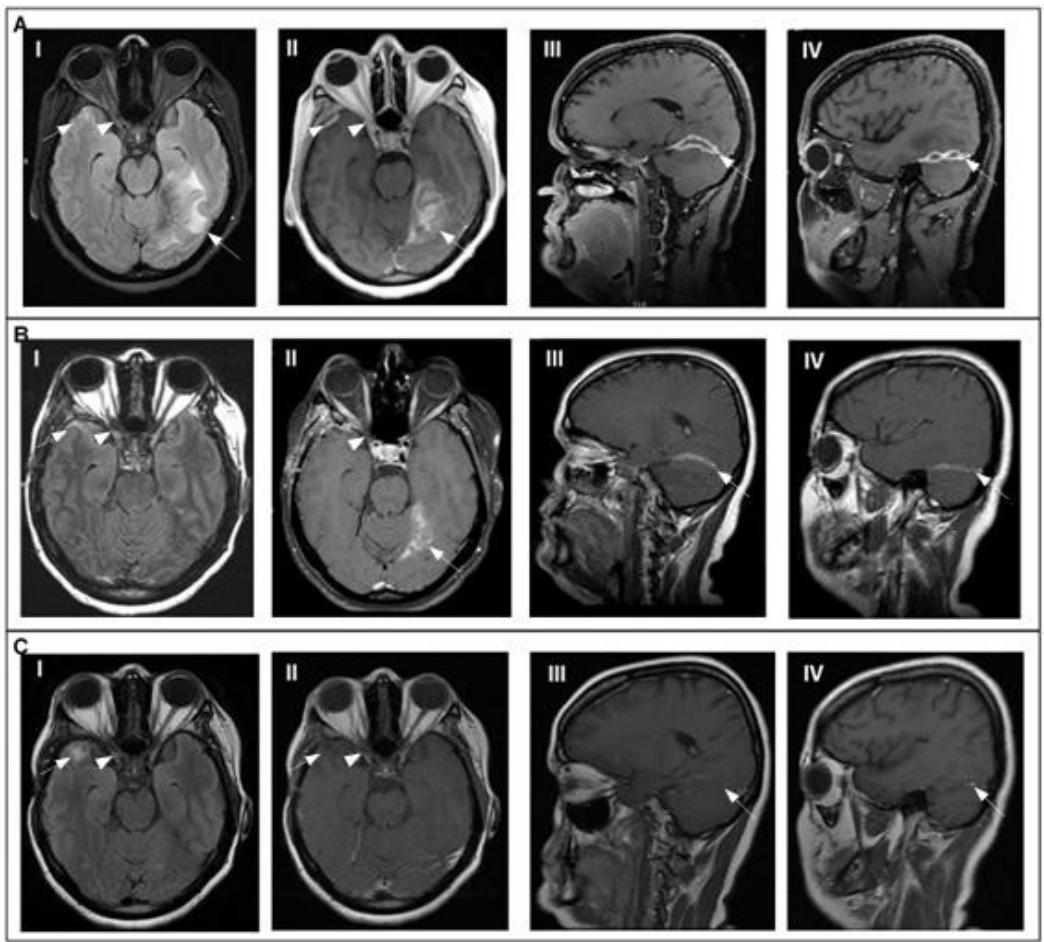

Figure 1. Brain MRI at disease onset (A); two months after steroid pulse therapy (B); and one year after treatment (C). At disease onset (A), there is a cortical and subcortical FLAIR hyperintensities (arrows in A.I) in the anterior right temporal pole and left

\footnotetext{
Hospital Federal dos Servidores do Estado, Rio de Janeiro, RJ, Brazil.

2 Universidade do Estado do Rio de Janeiro, Rio de Janeiro RJ, Brazil.

Nara Texeira Barbosa (D) http://orcid.org/0000-0002-1380-4142, Bárbara Camille Rocha Gomes (DD https://orcid.org/0000-0001-5641-1296, Marcelo Cagy https://orcid.org/0000-0002-1409-5974, Mariana Spitz (D) http://orcid.org/0000-0001-7548-2313, Ana Carolina Andorinho de Freitas Ferreira (DD https:// orcid.org/0000-0001-8474-4557

Correspondence: Nara Texeira Barbosa; Email: nara_tb@hotmail.com.

Conflict of interest: There is no conflict of interest to declare.

Authors' contributions: NTB: Conceptualization, data curation, formal analysis, investigation, resources, writing-original draft; BCRG: data curation, formal analysis, resources; MC: visualization, writing-review and editing; MS: visualization, writing-review and editing; ACAFF: Conceptualization, formal analysis, project administration, resources, writing-original draft, writing-review and editing

Received on September 02, 2020; Received in its final form on October 19, 2020; Accepted on November 02, 2020.
} 
temporal lobe. Those areas show T1 contrast enhancement (A.II) and highlight the pachymeningitis involving right temporal pole and parasellar region, including the orbital apex (A and B, arrow heads). Sagittal T1 with contrast (A.III and A.IV) show pachymeningitis in the left cerebellar tentorium (arrows), with subtle leptomeningeal involvement, characterized by sulci enhancement shown in the axial plane (arrows in A.II). Two months after pulse therapy (B) there is a reduction in the FLAIR hyperintensity and cortical/sulci enhancement in the left temporal lobe and a decrease of pachymeningeal thickening and enhancement. One year after pulse therapy (C) there is an almost complete resolution of meningeal abnormalities with a residual focal FLAIR hyperintensity in the right temporal pole, in the biopsy site.

IgG4 levels were normal. However, investigation was done under oral steroid use. Lymphoproliferative and exocrine gland disorders were excluded. Lung scintigraphy and CT were normal. Meningeal biopsy disclosed diffuse non-caseous granulomatosis. Intravenous steroid pulse improved ocular movements (Figure 2), but amaurosis persisted.

Neurologic manifestations represent less than $10 \%$ of sarcoidosis cases ${ }^{2}$. Isolated neurosarcoidosis is even rarer ${ }^{3}$.

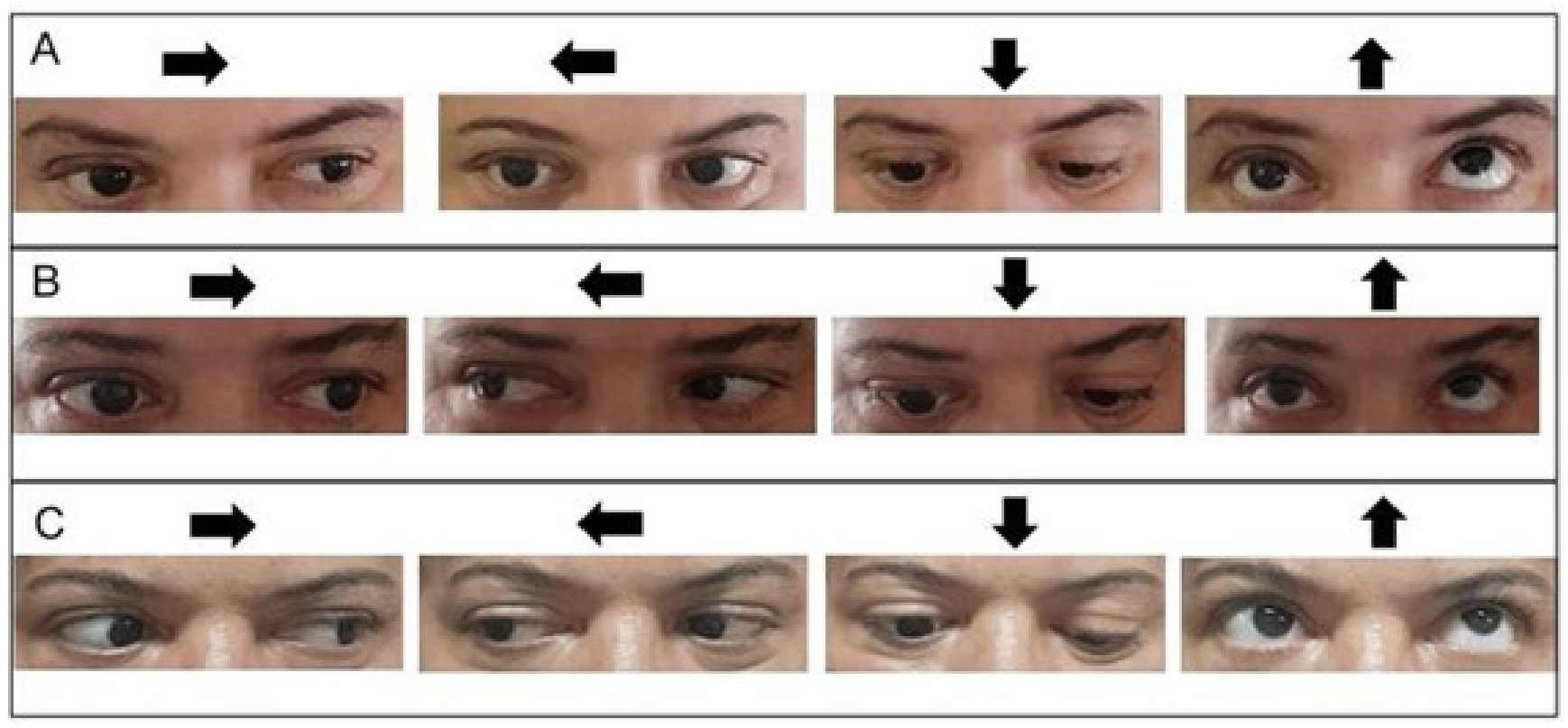

Figure 2. Evaluation of ocular motricity of the right eye (RE): A. Around 3 weeks after pulse intravenous methylprednisolone therapy. B. Two months after pulse therapy, a mild improvement, especially in abduction of RE. C. One year after pulse therapy, expressive improvement of horizontal motricity and remaining palsy of vertical gaze, particularly downward.

\section{References}

1. Zarei M, Anderson JR, Higgins JN, Manford MR. Cavernous sinus syndrome as the only manifestation of sarcoidosis. J Postgrad Med. 2002;48(2):119-21.

2. Chang CS, Chen WL, Li C Te, Wang PY. Cavernous sinus syndrome due to sarcoidosis: A case report. Acta Neurol Taiwan. 2009 Mar;18(1):3741.
3. Kidd DP. Sarcoidosis of the central nervous system: clinical features, imaging, and CSF results.J Neurol. 2018 Aug;265(8):1906-15. https:// doi.org/10.1007/s00415-018-8928-2 